\title{
Design and Application of Versatile Automatic Bin with Valve Splint Slide Way
}

\author{
Lei Zhao, Hua Zhang, Jie Yin and Hua Chen \\ Chongqing Electromechanical Vocational Institute, Chongqing, 402760, China
}

\begin{abstract}
A versatile modular automatic bin is designed for the valve processing and manufacturing industry, which can realize the functions of orderly storage, single separation, on-demand feeding and so on. It can also be combined with different types of manipulator to form an automatic loading and unloading workstation for each step of the valve fabrication to replace manual production. Targeting the real applications and conditions, in this work, the design requirements of silos are analyzed and the overall structure is designed. Experiments on the key component of the slide way are also carried out. Based on the data, the optimal inclination angle is determined. Besides, the material mechanism, the feeding mechanism and the pneumatic system are introduced in detail. Finally, the case study on the valve production enterprise is provided.
\end{abstract}

\section{Introduction}

The valve is an important part of an internal combustion engine, such as a motorcycle, and an internal combustion engine contains several to dozens of different valves. Valve processing relies on a variety of machine tools, is a large number of production, the cutting margin is small, the processing process is much and complex. In order to improve the production efficiency, guarantee the consistency of the product using manipulator and valve machine workstations to achieve valve automatic updown material, is now the valve manufacturers are working on a way. A very important structure is the hopper in the valve automatic fluctuation workstation. The hopper should have a certain number of valves, automatically separate the single valve, can adapt to different valve, the beat of the valve is faster than the machine tool, and so on. Chongqing electromechanical technical college municipal industrial robot integrated application technology promotion center design and in the enterprise to promote the application of the valve plywood slide type general automatic hopper.

\section{Valve automatic silo design requirements}

The valve product structure is shown in fig.1, The main dimensions of the product range are shown in table 1 .

Table 1. Main dimension variation range of valve.

\begin{tabular}{cc}
\hline Size & Size range \\
\hline $\mathrm{L}$ & $35-160 \mathrm{~mm}$ \\
$\mathrm{D}$ & $12-50 \mathrm{~mm}$ \\
$\mathrm{~d}$ & $3.5-12 \mathrm{~mm}$ \\
\hline
\end{tabular}

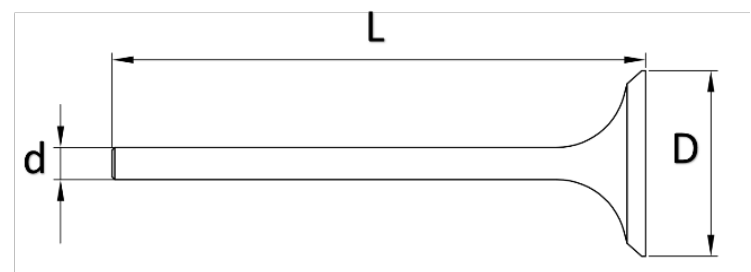

Figure 1. Valve key size.

The automatic silo shall have a certain storage capacity, which can automatically separate the material and the beat of the material is greater than the working beat of the machine tool in the integration work. With certain flexibility, it meets the production requirements of a certain size range valve, and ADAPTS to changing the demand of product model through simple adjustment. It has certain versatility, ADAPTS to many processes, can cooperate with various manipulator to install the interface, with the mechanical hand of many kinds of structure to cooperate to realize the valve automatic up and down material. Specific functional requirements are shown in table 2 .

Table 2. Function requirements of silo.

\begin{tabular}{cc}
\hline Project & Functional requirements \\
\hline $\begin{array}{c}\text { The loading capacity } \\
\text { Feeding interface }\end{array}$ & $\begin{array}{c}\text { Above } 30 \text { valves. } \\
\text { assembly line, can be replaced. } \\
\text { Points structure } \\
\text { Can automatically separate valve in silo. } \\
\text { interface } \\
\begin{array}{c}\text { Common interface, can be installed at least } \\
\text { Discharging the beat } \\
\text { volume }\end{array}\end{array}$ \\
Other & $\begin{array}{c}\text { No more than } 1000 \text { x } 500 \times 300 \mathrm{~mm} \\
\text { The working process can not damage the } \\
\text { valve, such as scratches. }\end{array}$ \\
\hline
\end{tabular}




\section{Overall structural design}

The overall structure of the automatic silo is mainly divided into four parts: the main body of the silo, the valve distributor, the silo installation interface, and the valve feeding mechanism[1-2]. The main body of the warehouse is the platform which carries the whole silo mechanism; The valve sorting mechanism is mainly used to separate the valves in the hopper arrangement. The silo installation interface is the interface between the whole silo and the external connection. The valve release mechanism is a separate valve cache, which is transmitted to the manipulator when the manipulator is needed.

The warehouse work process is divided into four steps. The first step loading material can be loaded manually into the hopper, or by the automatic line. The second step is to divide the material into a single valve. Step 3 cache, put in the buffer zone to wait for the feeding signal. In the fourth step, the hopper receives the feeding signal.

\section{Warehouse main body.}

The main body of the silo is the carrier of the whole automatic silo, as shown in fig. 2 .

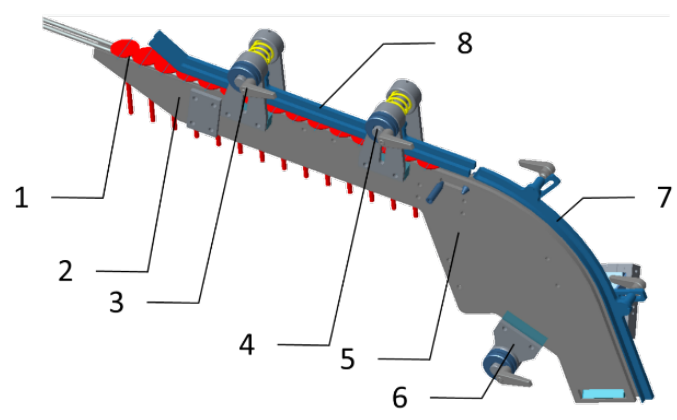

Figure 2. Main body of silo.

1 - the valve; 2 - extension of the feeding interface; 3 adjustment mechanism 1 for the track rod diameter; 4adjustment mechanism 2 for the track rod diameter; 5main support plate; 6- adjustment mechanism 3 for the track rod diameter; 7 - height adjustment block 1 in the material channel plate; 8- high adjustment block 2 for material channel plate.
The storage of valve is mainly made up of slide way, which consists of main support plate and auxiliary support plate. The cracks between the two plates constitute the valve storage and sliding way. The main support plate and auxiliary support plate have a certain inclination Angle, and the valve is automatically sliding down in the slide. The valve is overlapped in front and rear and is tilted in the slide. The sliding stability of the valve in the slide is mainly determined by the distance between the main support plate and the auxiliary support plate and the Angle of the slant. The force of the valve in the slide is shown in fig. 3 .
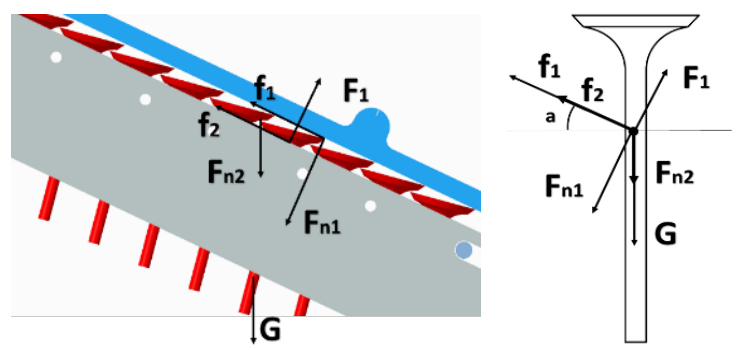

Figure 3. The valve is tried in the slide.

Valve in the sliding mainly by gravity, $\mathrm{G}$ formula one slide friction resistance, f2 feeding plate height adjustment block 2 frictional resistance, Fn1 feeding plate height adjustment block 2 pressure, Fn2 after a valve pressure, f1 track support [3]。

The valve can slide and slide smoothly in the slide, and there is no carton between the valve. The distance between the main support plate and the auxiliary support plate is adjustable. The distance between the height adjustment block and the slide is adjustable, and the tilt Angle of the support plate and the auxiliary support plate is fixed. The optimal tilt Angle is obtained by experiment, and the parameters used in the experiment are shown in table 3 .

Table 3. Experimental parameters of tilt Angle.

\begin{tabular}{cc}
\hline Parameter & The parameter value \\
\hline The valve specifications & $\begin{array}{c}\mathrm{D}=30 \mathrm{~mm} ; \mathrm{d}=8 \mathrm{~mm} ; \\
\mathrm{L}=90 \mathrm{~mm}\end{array}$ \\
$\begin{array}{c}\text { Spacing between support plates. } \\
\begin{array}{c}\text { The distance between the block and } \\
\text { the slide is highly adjusted. }\end{array}\end{array}$ & $8 \mathrm{~mm}$ \\
\hline
\end{tabular}

\subsection{Warehouse structure and slide design}

Table 4. Experimental data of tilt Angle.

\begin{tabular}{|c|c|c|c|c|c|}
\hline \multirow{2}{*}{ Tilt Angle } & \multicolumn{4}{|c|}{ Number of bunker valve. (psc) } & \multirow{2}{*}{$\begin{array}{l}\text { Valve loading and } \\
\text { unloading }\end{array}$} \\
\hline & 1 & 5 & 10 & 20 & \\
\hline $15^{\circ}$ & Don't slip & Don't slip & Don't slip & Don't slip & $\begin{array}{l}\text { The loading height is } \\
\text { moderate. }\end{array}$ \\
\hline $20^{\circ}$ & $\begin{array}{c}\text { Slow speed skating } \\
\text { movement }\end{array}$ & $\begin{array}{l}\text { Slow speed skating } \\
\text { movement }\end{array}$ & $\begin{array}{c}\text { Slow speed skating } \\
\text { movement }\end{array}$ & Slow speed skating movement & $\begin{array}{c}\text { Slow speed skating } \\
\text { movement }\end{array}$ \\
\hline $25^{\circ}$ & $\begin{array}{l}\text { Medium speed smooth } \\
\text { glide. }\end{array}$ & $\begin{array}{l}\text { Medium speed smooth } \\
\text { glide. }\end{array}$ & $\begin{array}{l}\text { Medium speed smooth } \\
\text { glide. }\end{array}$ & $\begin{array}{l}\text { Medium speed smoothly } \\
\text { Occasionally caton }\end{array}$ & $\begin{array}{l}\text { The loading height is } \\
\text { moderate. }\end{array}$ \\
\hline $30^{\circ}$ & $\begin{array}{l}\text { Medium speed smooth } \\
\text { glide. }\end{array}$ & $\begin{array}{l}\text { Medium speed smooth } \\
\text { glide. }\end{array}$ & $\begin{array}{l}\text { Medium speed smooth } \\
\text { glide. }\end{array}$ & Medium speed smooth glide. & $\begin{array}{l}\text { Medium speed smooth } \\
\text { glide. }\end{array}$ \\
\hline
\end{tabular}




\begin{tabular}{|c|c|c|c|c|c|}
\hline $35^{\circ}$ & $\begin{array}{l}\text { Quick and smooth } \\
\text { sliding }\end{array}$ & $\begin{array}{l}\text { Quick and smooth } \\
\text { sliding }\end{array}$ & $\begin{array}{l}\text { Quick and smooth } \\
\text { sliding }\end{array}$ & Quick and smooth bruising. & $\begin{array}{l}\text { The position is higher not } \\
\text { casual. }\end{array}$ \\
\hline $40^{\circ}$ & $\begin{array}{l}\text { Quick and smooth } \\
\text { sliding }\end{array}$ & $\begin{array}{l}\text { Quick and smooth } \\
\text { sliding }\end{array}$ & $\begin{array}{c}\text { quickly } \\
\text { A slight touch }\end{array}$ & $\begin{array}{c}\text { Quickly } \\
\text { A slight touch }\end{array}$ & $\begin{array}{l}\text { The position is higher not } \\
\text { casual. }\end{array}$ \\
\hline $45^{\circ}$ & $\begin{array}{l}\text { Quick and smooth } \\
\text { sliding }\end{array}$ & $\begin{array}{l}\text { Quick and smooth } \\
\text { sliding }\end{array}$ & $\begin{array}{l}\text { Fast sliding } \\
\text { Mild bruising }\end{array}$ & Quick and smooth bruising. & $\begin{array}{c}\text { The position is higher not } \\
\text { casual. }\end{array}$ \\
\hline
\end{tabular}

According to the experimental data in table 4, the Angle of tilt is too low, and there is no slip or slow speed slider. There is a carton, and the Angle of the tilt is too high. Finally, it is determined that the 30 degree is the best Angle, the sliding speed is moderate, the valve and the valve are not damaged, and the end of the rack is highly appropriate.

\subsection{The adjustment mechanism of the valve rod diameter of the material channel.}

There are three adjustment mechanism in the direction adjustment mechanism of the valve, which is installed on the main support plate and auxiliary support plate, and the three positions form a triangle. Used to adjust the spacing between the main support plate and the auxiliary support plate. When adjusting, the adjustment mechanism of valve rod diameter of the three feeding channels should be adjusted simultaneously.

The detailed structure of the adjusting mechanism of the valve rod diameter of the feed channel is shown in Fig. 4. Connections in the connection screw adjusting nut 16 , by rotating around the adjustment nut bearing the distance of 3,5 , or so bearing spring between the two 7 , high about bearing by cushion block 4 and the main support plate and the auxiliary support plate fixed connection. The spacing between the main support plate and the auxiliary support plate can be reduced by reducing the spacing between the main support plate and the auxiliary support plate when the adjusting nut is in advance. When the adjusting nut is turned out, the support plate and auxiliary support plate are increased to increase the spacing between the support plate and the auxiliary support plate under the action of the spring. When after the completion of the adjustment nut, by the handle locking bolt 2 lock, lock the adjusting nut will not be able to turn, thus guarantees the stability of the feeding interval, not affected by vibration and interference factors. [4].

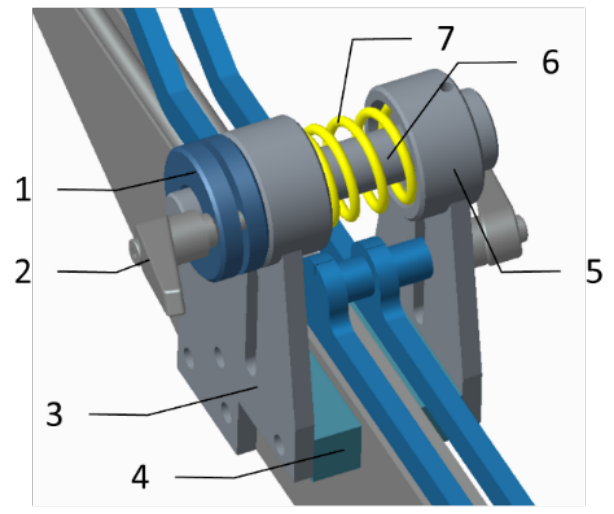

Figure 4. Detail drawing of valve rod diameter direction adjustment mechanism. 1-adjusting nut; 2- handle lock bolt; 3- left support; 4padding block; 5- right support; 6- connect the screw; 7 the spring

\subsection{Height adjustment structure of material channel plate}

The height adjustment mechanism of the feeding channel plate is mainly distributed in two areas, the valve hopper storage area and the valve separation zone. As shown in fig.5, valve bin area is mainly used to control the feeding plate height adjustment block 2 and track spacing, feeding plate height adjustment of block 2 through the handle locking bolt fixed on the bearing the chute on the right, through the handle locking bolt spacing adjustment. Valve (material feeding pan height adjustment valve is mainly used to control a single separation of the guidance, the main structure as arc, with same slideway arc, through the chute bracket block, cooperate to handle lock bolt spacing adjustment.

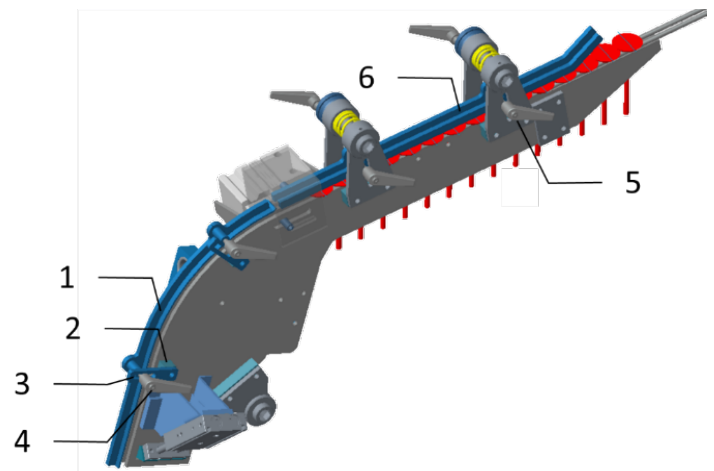

Figure 5. Height adjustment structure of material channel plate.

1 - height adjustment block 1 in the material channel plate; 2- adjust the block height; 3- bracket block; 4handle lock bolt; 5- handle lock bolt; 6- height adjustment block of material channel plate. 2

\section{The design of the sorting mechanism.}

The separation mechanism mainly separates the valve from one in the silo, and its main structure is shown in fig.6. The connecting plate is connected to the separator cylinder, and the connecting plate is fixed on both sides of the feed rod and the lower retaining rod.
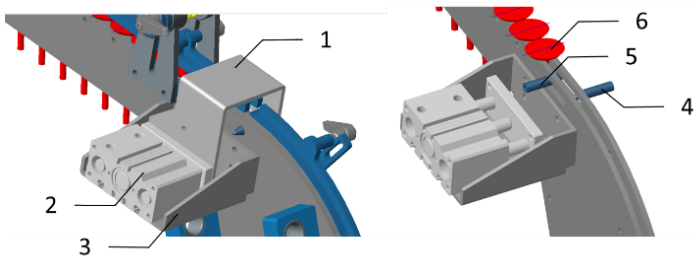

Figure 6. Structure diagram of material structure. 
1-connecting plate; 2 - sorting cylinder; 3 - bearing; 4 lower retaining rod; 5- upper retaining rod; 6 - valve;

The working process is divided into three processes: the block process, the separation process and the feeding process. Block process: the feed cylinder is outstretched, and the upper retaining rod is inserted into the slide way to stop the valve sliding in the slide. Material process: material cylinder retracted, keep-off lever on the exit ramp, keep-off rod into the chute, the valve under the action of gravity downward slide in the slide, by keep-off rod under the single valve is then entered the keep-off between rod and keep-off under the rod., hanging on the feeding process, cylinder block other valves in the stem slides out stopped bin, the downside of material rod back out by block valve between keep-off rod up and down, so a single valve is separated.

\section{Design of feeding mechanism}

The feeding mechanism is shown in fig.7, consisting of block, base and block cylinder. The feeding mechanism mainly blocks the valve that has been separated from the silo, so that the individual valve can be cached before discharging, and the valve is released when the external manipulator needs.

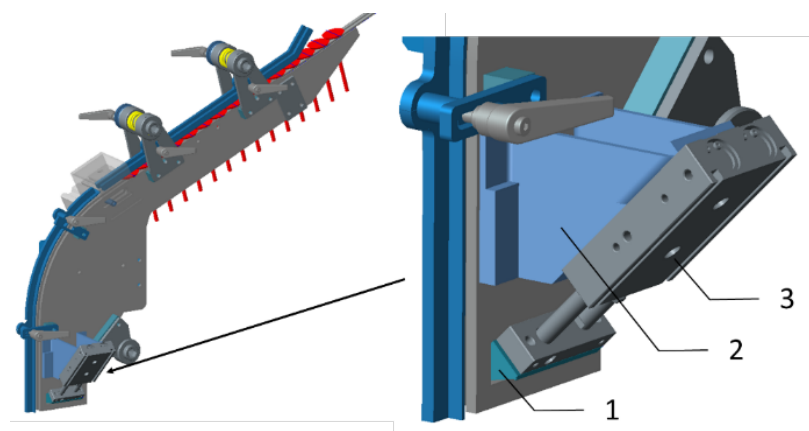

Figure 7. Structure diagram of feeding mechanism.

1-block block; 2 - the base; 3 - block cylinder

\section{Pneumatic system}

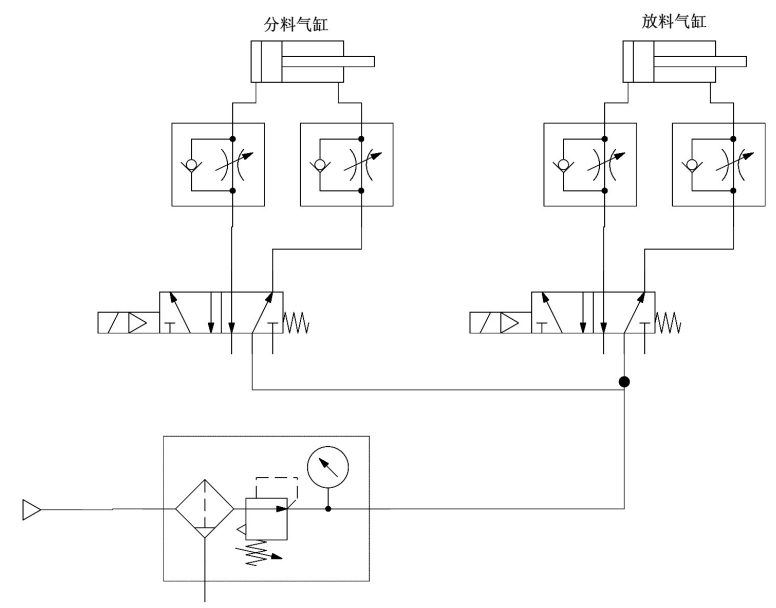

Figure 8. Pneumatic system of silo.
The pneumatic system is shown in fig.8 [5], and the actuator cylinder has two parts, one part cylinder and one feeding cylinder. The separation cylinder selects triaxial cylinder, and the feeding cylinder is selected as a biaxial cylinder. The exhaust throttle valve is adopted at both ends of the cylinder to adjust the cylinder sticking out. The solenoid valve chooses two - digit five - way. The default state of the separating cylinder and the discharge cylinder is extended [6-7].

\section{Application}

The plywood slide - type automatic silo is designed according to the actual demand of the enterprise. The warehouse structure is simple, easy to adjust, strong in use, high delivery efficiency and good modularity. It can be combined with various forms of valve and upper and lower materials to realize automation and meet the needs of enterprises [8-9] . servo linear manipulator [10], front line manipulator [11]. Fig.9 is the site application of the warehouse in chongqing yongfeng elite valve co., LTD.

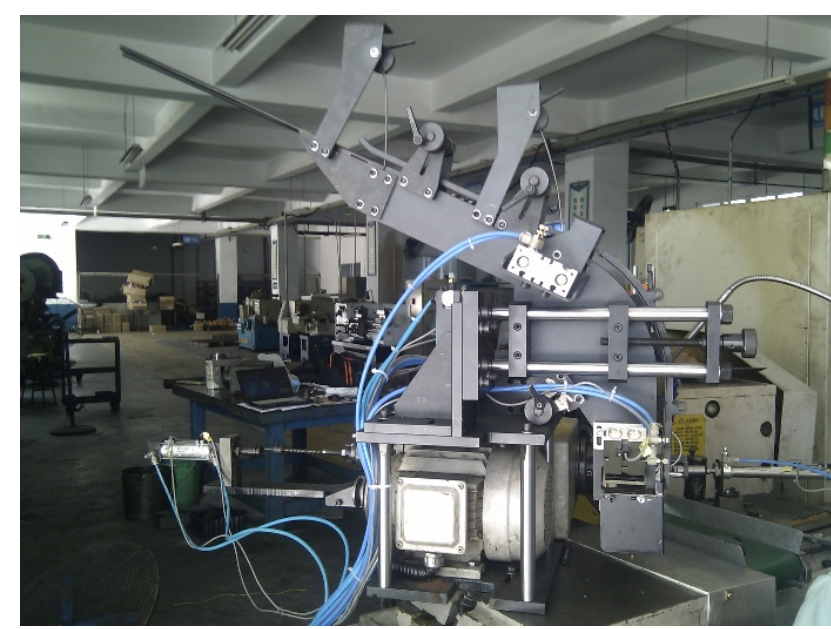

Figure 9. Field application of hopper in valve production enterprise.

\section{Acknowledgement}

This research was financially supported by the education and teaching reform project of Chongqing Education Commission (171042). Industrial robot is integrated in chongqing higher vocational technical college application technology promotion center project.

\section{References}

1. Wen Bangchun. Mechanical design manual (5th edition) $[\mathrm{M}]$. Beijing: mechanical industry press, 2011.

2. Zhan Yougang. Pro / ENGINEER wildfire version 5.0 mechanical design course [M]. Beijing: mechanical industry press, 2015.

3. Theoretical mechanics teaching and research room of Harbin Institute of Technology. Theoretical mechanics (8th edition) [M]. Beijing: advanced education publishing house, 2016. 
4. Pu Lianggui, Chen Guoding, Wu Liyan. Mechanical design (9th edition) [M]. Beijing: higher education press, 2013.

5. FESTO, Germany. Fluid SIM Pneumatics simulation design software.

6. Zuo Jianmin. Hydraulic and pneumatic transmission (4th edition) $[\mathrm{M}]$. Beijing: mechanical industry press, 2014.

7. SMC (China) co., LTD. Modern practical pneumatic technology [M]. Beijing: mechanical industry press, 2014.

8. Zhao Lei, Zhang Hua. Design of automatic pneumatic feeding system for valve cone grinding machine [J]. Modern machinery, 2016(3): 66-68.
9. Zhao Lei. Design of feeding manipulator for valve cone grinding machine $[\mathrm{J}]$. Rubber and plastic technology and equipment, 2017(16): 56-58.

10. Duan Chengyan, Wang Dongsheng, Liu Chunxiang, Yue Caixia, Zhang Chunfu. The overall structure design and modeling of the upper and lower material manipulator $[\mathrm{J}]$. Mechanical engineer, 2014 (12): 138-140.

11. Han Hongluan. Integration and application of industrial robot workstation system [M]. Beijing: chemical industry press, 2017. 